\title{
Macronutrient Adequacy of Elite Sri Lankan Swimmers
}

\author{
${ }^{1} \mathrm{~V}$ Ganegama Arachchi, ${ }^{2} \mathrm{~S}$ Wasalathanthiri and ${ }^{3} \mathrm{~T}$ Makuloluwa \\ ${ }^{1}$ Institute of Sports Medicine, Torrington place, Colombo 7, Sri Lanka \\ ${ }^{2}$ Department of Physiology, Faculty of Medicine Colombo, Sri Lanka \\ ${ }^{3}$ Faculty of Allied Health Sciences, Kothalawala Defense University, Sri Lanka
}

\begin{abstract}
Nutrition seems to play an important role in health and performance of swimmers. The present study assessed the macronutrient intakes and calorie adequacy of swimmers of Sri Lankan national pool. 38 swimmers (16 males and 22 females) were studied during formal training, 3 weeks prior to an athletic event. Body height, weight and fat percentage were calculated. Dietary intake was assessed by $24-h r$ dietary recall and energy expenditure by considering the daily activities and MET values. Data were analyzed by SPSS statistical package. Means and standard deviations were calculated for total energy intakes and total energy expenditures for males and females separately and the statistical differences were determined by the paired $t$ test. The mean $( \pm S D)$ age, body mass index and body fat percentages of male and female swimmers were $16.8 \pm 1.4$ and $16.7 \pm 1.5$ years, $21.44 \pm 1.87$ and $21.86 \pm 3.41 \mathrm{~kg} / \mathrm{m}^{2}$ and $13 \pm 3.07 \%$ and $20.5 \pm 1.93 \%$ respectively. Although the mean energy expenditure was higher than the mean energy intake in males

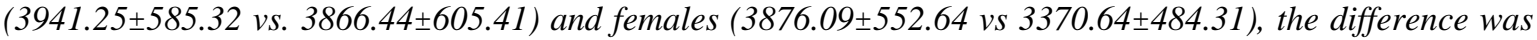
statistically significant only in females $(p=0.002)$. Four out of 16 males and all females were in negative energy balance. When percentage of energy derived from three major macronutrients were analyzed, approximately 77\%, 9\% and 14\% were derived from carbohydrates, proteins and fats respectively. In conclusion, although energy balance is not satisfactory in both groups, it is seriously compromised in female swimmers. Low protein intake in both groups has to be considered seriously, as these swimmers belong to a young age group.
\end{abstract}

KEYWORDS: Energy intake, energy expenditure, macronutrients, elite swimmers 


\section{INTRODUCTION}

Sports performance is known to be affected by many factors. Optimum nutrition is one of the important factors to ensure optimum performance in sports. However, studies done globally have shown that athletes fail to achieve the daily nutrient intakes recommended by the guidelines.

Although meeting the energy needs is the first nutritional priority for optimum sports performance, energy intakes of athletes show wide variation (Grandjean, 1997). Athletes, especially who are engaged in endurance sports are advised to consume a diet rich in carbohydrates $(\mathrm{CHO})$ in order to replenish the muscle and liver glycogen stores. A diet from which $70 \%$ of total calories derived from $\mathrm{CHO}$ is advised for elite endurance athletes who undergo regular training as $\mathrm{CHO}$ is the preferred fuel for muscle metabolism in high intensity exercise (Economos et al., 1993). The recommended dietary protein requirement of adult athletes is 1.0 to $2.0 \mathrm{~g} / \mathrm{kg}$ body mass (Colombani \& Mettler, 2011). Since the age range in elite swimmers appears to be lower when compared to other sports (Vrantza, 2002: Paschoal \& Amancio, 2004) additional protein may be required for the completion of their growth and development.

Although nutrition in elite swimmers is a reasonably researched area, a very few studies (Ousley-Pahnke et al., 2001) have focused on the importance of modification of dietary requirements according to varying training volumes. Furthermore, literature on nutritional requirements of sprint swimmers is extremely sparse. Therefore the objectives of the present study were to examine the nutritional status of national level sprint swimmers in order to assess the nutrient intake in relation to the recommendations and to the nutrient utilization.

\section{METHODOLOGY}

This is part of a prospective cohort study conducted at the Torrington Sports Complex and at the Sugathadasa Stadium in Colombo. Data were collected during formal training 3 weeks prior to a national athletic event in which the swimmers trained for 2.5 hours per day on 6 days of the week. The study sample consisted of 38 swimmers (16 males and 22 females) of the national pool in Sri Lanka recruited on a voluntary basis. Ethical clearance was obtained from the review committee of the Faculty of Medical Sciences of University of Sri Jayewardenepura. Informed consent was obtained from the participants at the time of recruitment to the study.

Major areas of the study protocol were anthropometric measurements, dietary information and nutrient intake, and energy expenditure.

\section{Anthropometry}

Body height was measured to the nearest 0.1 centimeter with a wall mounted stadiometer and weight was recorded to the nearest 0.1 kilograms with an electronic medical scale. Body mass index (BMI) was calculated using height and weight measurements. Body fat percentage was calculated using skin fold thickness measurements at four different sites (triceps, abdomen, suprailliac region and thigh) by using a Harpendon skin fold caliper.

\section{Dietary intake}

Dietary intake was assessed by the 24 hour dietary recall method. Sports personnel were asked to record the quantities of food and beverages taken on three non-consecutive days (two days during the week and one day over the weekend). Instructions on how to record food and beverages using standard 
household units were introduced to them prior to data collection. The dietary recalls were analyzed using food base 2000 software (Institute of Bahrain Chemistry, London)updated for Sri Lankan food to determine the intake of energy and nutrients over three days. Dietary intake was expressed as the consumption per person per day.

\section{Energy expenditure}

The subjects were asked to record all activities from the time of waking up to the time of going to bed. The total energy expenditure of activities throughout a training day was calculated by multiplying the scientifically determined metabolic equivalents (METS) for each activity by the body weight of the subject and the duration of the activity in hours.

\section{Data Analysis}

The data was analyzed by SPSS computer program (version 20). Means and standard deviations were calculated for total energy intakes and total energy expenditures for male and female swimmers separately. The statistical differences between energy intakes and expenditures were determined by the paired t test. A p-value of $\leq 0.05$ was considered to be statistically significant.

\section{RESULTS}

The mean $( \pm \mathrm{SD})$ age of male and female swimmers was $16.8 \pm 1.4$ and $16.7 \pm 1.5$ years respectively. The mean $( \pm \mathrm{SD})$ body mass index of males and females was $21.4 \pm 1.9$ and $21.9 \pm 3.4 \mathrm{~kg} / \mathrm{m}^{2}$ respectively, and the body fat percentage of males and females was $13 \pm 3.1 \%$ and $20.5 \pm 1.9 \%$ respectively.

Mean daily energy intake and energy expenditure of male and female swimmers are shown in table 1. Although the mean energy expenditure was higher than the mean energy intake in both males and females, the difference was statistically significant only in female swimmers. In supportive of this finding, 04 out of 16 males and all females were in negative energy balance.

Table 1. Energy intake and energy expenditure according to gender

\begin{tabular}{|c|l|c|l|}
\hline Gender & Variable & Mean $( \pm)$ & P value \\
\hline Males (16) & $\begin{array}{l}\text { energy } \\
\text { intake } \\
\text { energy } \\
\text { expenditure }\end{array}$ & $3866 . \pm 605$ & 0.645 \\
\hline Females(22) & $\begin{array}{l}\text { energy } \\
\text { intake } \\
\text { energy } \\
\text { expenditure }\end{array}$ & $3371 \pm 484$ & 0.002 \\
\hline
\end{tabular}

The percentage of energy derived from three major macronutrients is shown in table 2 . No significant differences were seen for the percentage of energy derived from carbohydrate, fat and proteins in male and female swimmers.

Table 2. Percentage contribution of carbohydrate, fat and protein to the total daily energy intake of swimmers

\begin{tabular}{|l|c|c|c|}
\hline & $\begin{array}{c}\text { Carbohy } \\
\text { drate }\end{array}$ & Fat & Protein \\
\hline Males & $76.9 \pm 6.5$ & $14.4 \pm 5.8$ & $8.9 \pm 1.8$ \\
\hline Females & $77.3 \pm 11$ & $13.4 \pm 2.1$ & $9.3 \pm 1.7$ \\
\hline
\end{tabular}

\section{DISCUSSION}

Optimum intake of energy and macronutrients are important in athletes to maintain body weight to replenish glycogen stores and to build and repair tissues. The present study is an attempt to pinpoint nutritional inadequacy as an important contributory factor for non-optimal sports performance in Sri Lankan swimmers.

Both male and female swimmers in the Sri Lankan national pool seem to be in a very young age group. This observation is 
shared by studies done elsewhere (Vrantza, 2002: Paschoal \& Amancio, 2004) raising the question whether elite swimmers belonging to a lower age group is a trend observed globally. In addition to sports performance, increased energy and nutrient needs for physiologic growth and development is also a factor to be considered in young sports personnel.

Results of the study show that the body mass index and percentage of body fat were within the normal range. However, body fat percentage was higher in females compared to males as expected. In contrast to most other sports, higher fat mass in swimmers is thought to provide greater floatation and therefore lower energy expenditure during swimming (Wells et al., 2006).

Although energy consumption should match the energy intake for optimum health and sports performance of athletes, in the present study, the energy balance was not satisfactory in both male and female swimmers. A negative energy balance is reported to be common among endurance athletes, female athletes and in athletes engaged in sports in which body composition and size should be maintained by dietary restrictions $(8,9)$.

When the percentage energy derived from three major nutrients was considered, the $\mathrm{CHO}$ intake was more than the recommended range in both sexes. High $\mathrm{CHO}$ intake ensures increased muscle glycogen synthesis and a rich glycogen store. However, the results show that only $8-9 \%$ of energy is derived from proteins indicating that the protein intake is lower in this group of swimmers when compared to other macronutrients. This is a finding which requires consideration, especially in this group where the dietary protein requirements would have to be increased than the adult values to accommodate growth and development in these young swimmers.

The American Dietetic Association, Dietitians of Canada and the American College of Sports Medicine jointly recommend appropriate selection of foods and fluids, meal timings and supplement choices (10) as additional factors for optimal health of athletes and their athletic performance. Although nutrient intake is assessed in this study, not assessing the other factors that influence the performance during training and competition is a limitation.

This study stresses the importance of providing nutritional counseling to elite swimmers not only to improve their swimming performance but also to facilitate optimum growth and development.

\section{REFERENCES}

GRANDJEAN AC. Diets of elite athletes: has the discipline of sports nutrition made an impact? J.Nutr. 1997; 127(5) : 874S-877S.

ECONOMOS CD, BORTZ SS, NELSON ME. Nutritional practices of elite athletes. Practical recommendations. Sports Med. 1993;16 (6): 381-99.

COLOMBANI PC, METTLER S. Role of dietary proteins in sports. Int $\mathrm{J}$ VitamNutr Res. 2011; 81(2-3): 120-124. doi: $10.1024 / 0300-9831 / \mathrm{a} 000060$

VRANTZA, PATROULA. Nutrient intake and anthropometric characteristics of adolescent Greek swimmers. The Journal of the Dietitians Association of Australia. Nutrition \& Dietetics . 2002; 113 -114.

PASCHOAL, VC, AMANCIO OM. Nutritional status of Brazilian elite swimmers. J Am Diet Assoc . 2004; 101(3): 351-354. Int $J$ Sport NutrExercMetab. 2001;14(1): 81-94. 
OUSLEY-PAHNKE L' BLACK DR, GRETE BECK RJ. Dietary intake and energy expenditure of female collegiate swimmers during decreased training prior to competition. J Am Diet Assoc. 2001.

WELLS, GREG, SCHNEIDERMANWALKER, JANE, PLYLEY, MIKE J. Normal Physiological Characteristics of Elite Swimmers. Pediatric Exercise Science. 2006; 18(1) $30-23$.

KREIDER RD, WILBOM CD, TAILOR L et al. ISSN exercise \& sport nutrition review: research and recommendations. Journal of the International Society of Sports Nutrition. . 2010;7:7

LOUCKS AB, KLENS B, WRIGHT HH. Energy availability in athletes Sports Science. 2011; 29(S1): 17-27.

Dieticians of Canada American College of Sports Medicine, American Dietetic Association. Nutrition and Athletic Performance-.J. Joint Position Paper . 2008; 1-26. 